\title{
Production of Flavonoids and Terpene Lactones from Optimized Ginkgo biloba Tissue Culture
}

\author{
Shuiyuan $\mathrm{CHENG}^{1}$, Weiwei $Z \mathrm{HANG}^{1}$, Nannan $\mathrm{SUN}^{2}$, Feng XU ${ }^{2 *}$, \\ Linling $\mathrm{LI}^{3}$, Yongling $\mathrm{LIAO}^{2}$, Hua $\mathrm{CHENG}^{3}$ \\ ${ }^{1}$ College of Forest Resources and Environment, Nanjing Forestry University, Nanjing, 210037, China \\ ${ }^{2}$ College of Horticulture and Gardening, Yangtze University, Jingzhou 434025, Hubei, China \\ ${ }^{3}$ Economic Forest Germplasm Improvement and Comprehensive Utilization of Resources of Hubei Key Laboratory, Huanggang Normal \\ University, Huanggang 438000, Hubei, China; xufeng198@126.com (*corresponding author)
}

\begin{abstract}
This study investigated the effects of various culture conditions on the growth and the production of flavonoids and terpene lactones in the callus of Ginkgo biloba. Callus induced from embryos displayed distinct morphological and physiological responses. MS medium with different plant growth regulators showed a significant effect on the quality and growth of callus. The optimal medium for inducing embryo-derived callus was MS with $2.0 \mathrm{mg} / \mathrm{L}$ naphthalene acetic acid (NAA) and $2.0 \mathrm{mg} / \mathrm{L} 6$ benzylaminopurine (6-BA), and the culture medium MS+NAA $(2.0 \mathrm{mg} / \mathrm{L})+6-\mathrm{BA}(1.0 \mathrm{mg} / \mathrm{L})$ was better for the subculture of callus than other culture media tested in this study. In addition, both plant growth regulators and subculturing cycle strongly influenced the production of flavonoids and terpene lactones in the callus. The best subculturing cycle and the optimum culture medium for production of flavonoids and terpene lactones was $30 \mathrm{~d}$ and MS+NAA $(2.0 \mathrm{mg} / \mathrm{L})+6-\mathrm{BA}(1.0 \mathrm{mg} / \mathrm{L})$, respectively. These findings provided an important technical support for obtaining the callus cell line from G. biloba embryo that is the richest in flavonoids and terpene lactones.
\end{abstract}

Keywords: callus, culture medium, flavonoids, Ginkgo biloba, subculturing cycle, terpene lactones

\section{Introduction}

Ginkgo biloba L., also called maidenhair tree, is a deciduous gymnosperm that is valued in China. As one of the oldest tree species in the world, G. biloba enjoys the unique reputation of being a 'living fossil' (Bilia, 2002). G. biloba has great ornamental and medicinal value. The Ginkgo extract EGB761 contains two important active pharmaceutical components, flavonoids and terpene lactones (Van Beek and Montoro, 2009), which can promote blood circulation and cerebral metabolism. These compounds make EGB761 as an effective treatment for cerebrovascular diseases, such as coronary heart disease and high blood pressure (Mahadevan and Park, 2008; Lu et al., 2011; Nakanishi, 2005). However, the contents of flavonoids and terpene lactones are quite low in Ginkgo grown under natural conditions. In addition, the extraction procedure for these compounds is complicated. The development and utilization of the pharmaceutical ingredients of Gingko are greatly limited by the place where it grows and seasons (Camper et al., 1997). Therefore, industrialized production of flavonoids and terpene lactones through tissue culture is a significant direction in the study of Ginkgo (Sun et al., 2011).
In recent years, many studies on inducing the callus of Ginkgo and cell suspension culture have been conducted. Great progress has been achieved in cultivating Ginkgo organs and tissues for the production of secondary metabolites. Chen et al. (1997) have proposed the best culture medium and explants for inducing callus and producing flavonoids from the leaf, stem and root in Ginkgo. Kim et al. (1998, 1999) and Hao et al. (2009, 2010) have also reported that several exogenous inducing factors, including fungus, low temperature, ultraviolet light, abscisic acid, and heavy metal ions, can promote the accumulation of flavonoids in Ginkgo cell suspension cultures or callus tissue. Research has also been conducted on the in vitro culture of Ginkgo tissues for the production of terpene lactones. Carrier et al. (1991) first found ginkgolide A and traces of ginkgolide B in G. biloba suspension culture extracts. Subsequently, a more constant production of ginkgolide $\mathrm{A}$, compared with intact trees, has been achieved using petiole-derived G. biloba cell cultures (Park et al., 2004). Recently, several biotic and abiotic elicitors have been used to increase the accumulation of bilobalide and ginkgolides in G. biloba cell suspensions (Kang et al., 2006a, 2009). Many studies have focused on producing flavonoids or terpene lactones respectively using Ginkgo tissue culture, little is known about the cultivation factors affecting both of 
flavonoid and terpene lactone contents. Specifically, the effects of hormone variety and concentration on both of flavonoid and terpene lactone contents remain unclear. Therefore, the present study used Ginkgo embryo as the explant and investigated the effects of different hormone combinations on callus induction, subculture, and flavonoid and terpene lactone contents in the callus. This study aims to provide a theoretical foundation and optimum material for the fast and efficient production of flavonoids and terpene lactones from Ginkgo by selecting the callus cell line that is richest in these compounds.

\section{Materials and methods}

\section{Plant materials}

Seeds of G. biloba were harvested in China (Botanical Garden of Yangtze University, Jingzhou) in September and kept at $4{ }^{\circ} \mathrm{C}$. The seeds were used after 2 and 5 months of storage when the embryos were at the cotyledonary stage. The seed surface was sterilized with $70 \%(\mathrm{v} / \mathrm{v})$ ethanol for 1 $\mathrm{min}$, followed by $3 \%(\mathrm{v} / \mathrm{v})$ sodium hypochlorite for $15 \mathrm{~min}$, and then rinsed six times with sterile distilled water. The embryo was separated from sterilized seed with sterile knife and forceps, cut longitudinally and then used for inducing callus.

\section{Tissue Culture Conditions}

The embryos were excised and transferred to the (MS) solid medium $(\mathrm{pH}$ 5.8) supplemented with $3 \%(\mathrm{w} / \mathrm{v})$ sucrose, $0.3(\mathrm{w} / \mathrm{v})$ gelrite and two various concentrations of NAA and 6-BA (Murashige and Skoog, 1962). The concentration combinations of NAA and 6-BA were shown in Tab. 1. The cultures were incubated in the light (100 $\mu \mathrm{mol} \mathrm{m} \mathrm{s}^{-2} \mathrm{~s}^{-1}$ with a $16 / 8 \mathrm{~h}$ light/dark photoperiod at $24 \pm 1$ ${ }^{\circ} \mathrm{C}$, and then subcultured after every 5 weeks. Callus induction including weight, colour and percentage of explants producing callus were recorded after 5 weeks.

Tab. 1. Different hormone concentration combination of MS medium

\begin{tabular}{ccc}
\hline $\begin{array}{c}\text { Culture medium } \\
\text { Code }\end{array}$ & $\begin{array}{c}\text { NAA } \\
(\mathrm{mg} / \mathrm{L})\end{array}$ & $\begin{array}{c}6-\mathrm{BA} \\
(\mathrm{mg} / \mathrm{L})\end{array}$ \\
\hline A1 & 1.0 & 0.5 \\
$\mathrm{~A} 2$ & 1.0 & 1.0 \\
$\mathrm{~A} 3$ & 1.0 & 2.0 \\
B1 & 2.0 & 0.5 \\
B2 & 2.0 & 1.0 \\
B3 & 2.0 & 2.0 \\
C1 & 3.0 & 0.5 \\
C2 & 3.0 & 1.0 \\
C3 & 3.0 & 2.0 \\
\hline
\end{tabular}
Lactones

Extraction and Determination of Flavonoids and Terpene

The collected callus was immediately dried for $72 \mathrm{~h}$ at 40 ${ }^{\circ} \mathrm{C}$ and then ground into powder liquid nitrogen. The powder $(0.1 \mathrm{~g})$ of dried ginkgo callus was dissolved in $40 \mathrm{~mL}$ acidulated methanol by sonication at $70{ }^{\circ} \mathrm{C}$ for $90 \mathrm{~min}$. The sample solution was then filtered through $0.2 \mu \mathrm{m}$ filter membrane (Millipore, Nylon) filters for HPLC analysis. Flavonoid contents were quantified by HPLC using a previously described method (Xu et al., 2012). Quercetin, kaempferol, and isorhamnetin were selected as standard samples because many different flavonol glycosides in $G$. biloba are derivatives of these three flavonol aglycones. Flavonoid content was calculated by multiplying the total content of quercetin, kaempferol, and isorhamnetin (supplemental Tab. S1) by 2.51 (Van Beek, 2002) and expressed as percents of DW percentages. Ginkgolide A (GA), ginkgolide $B(\mathrm{~GB})$, ginkgolide $\mathrm{C}(\mathrm{GC})$ and bilobalide (BB) were extracted and quantified by gas chromatography with a wide bore capillary column (Liao et al., 2008). The content of terpene lactones was the sum of the contents of GA, GB, GC, and BB (supplemental Tab. S2) and expressed as DW percentages. All the tests were carried out in triplicate, and data represent the means \pm standard errors (SE).

\section{Statistical analysis}

Data were analysed with one-way ANOVA using SPSS 11.0 (SPSS Inc., Chicago, Illinois) for Windows and means were compared with Duncan's multiple range test at $P \leq$ 0.05 .

\section{Results}

Effect of Different Concentrations of Naphthalene Acetic Acid (NAA) and 6-Benzylaminopurine (6-BA) on Callus Induction

The Ginkgo embryo was inoculated in a culture medium with different concentrations of NAA and 6-BA. A callus appeared in some explants after one week, and the shape of the callus was quite noticeable after 2 weeks. The callus (Fig. 1A) induced by the embryo was yellow green and had better dispersion and resistance to browning than the embryoidal cells that developed into dark green callus (Fig. 1B) with dark green. Our results showed that different culture media had different effects on the efficiency of callogenesis and callus quality. The efficiency of callogenesis and growth increment of callus after 3 weeks are shown in Tab. 2. The callus induced in culture medium B3 (MS + NAA $2.0 \mathrm{mg} / \mathrm{L}+6-\mathrm{BA} 2.0 \mathrm{mg} / \mathrm{L}$ ) had the highest efficiency, maximum growth increment, greatest quantity, and best effect of yellow green and granulation with significant difference $(P \leq 0.05)$ than those from other culture media. Thus, culture medium B3 is considered the best culture medium for inducing callus from Ginkgo embryo in this study.

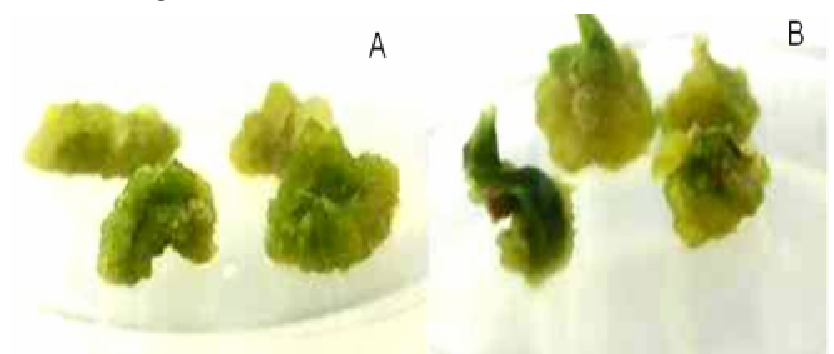

Fig. 1. The callus (A) derived from embryo and embryoidal cells developed into callus (B) of Ginkgo biloba 
90

Effect of Different Concentrations of NAA and 6-BA on the Successive Growth of Callus

The calluses in culture media $\mathrm{B} 2$ and $\mathrm{B} 3$ at $2.0 \mathrm{mg} / \mathrm{L}$ NAA showed the best growth, with light yellow green color, loose texture, and obvious granulation (Fig. 2A). Most of the calluses in culture media $\mathrm{C} 1, \mathrm{C} 2$, and $\mathrm{C} 3$ at $3.0 \mathrm{mg} / \mathrm{L}$ NAA were light green with loose texture and obvious granulation, whereas some were dark green with compact texture and vigorous growth (Fig. 2B). Most of the calluses cultured in media A1, A2, and A3 were slightly green, whereas some were dark green with compact texture (Fig. $2 \mathrm{C}$ ). Overall, the results showed that culture medium B2 $(\mathrm{MS}+\mathrm{NAA} 2.0 \mathrm{mg} / \mathrm{L}+6-\mathrm{BA} 1.0 \mathrm{mg} / \mathrm{L}$ ) is the best medium for callus subculture.

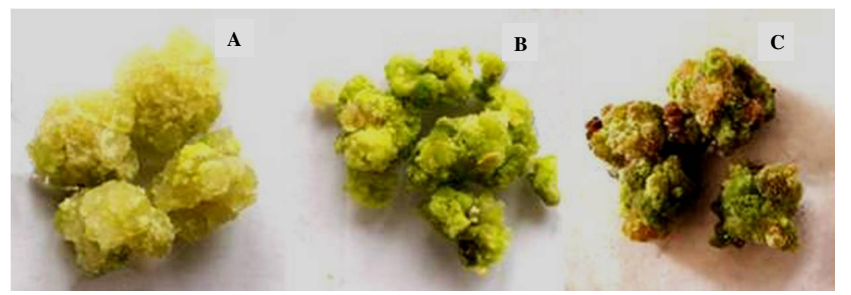

Fig. 2. The growth of Ginkgo callus state after subculture on different culture medium. (A) The Ginkgo callus on culture medium B. (B) The Ginkgo callus on culture medium C. (C) The Ginkgo callus on culture medium A

The vigorous callus in culture medium B3 was selected for subculture in the culture media with different concentrations of hormones. The weight of the callus was recorded on the $15^{\text {th }}, 30^{\text {th }}$ and $45^{\text {th }}$ days. The growth of the calluses in the different concentrations of hormones increased as the subculture period was prolonged (Fig. 3). The callus in culture medium B2 had the highest and significant higher $(P \leq 0.05)$ dry weight on the $15^{\text {th }}, 30^{\text {th }}$, and $45^{\text {th }}$ days after the subculture than those calluses in other culture media. The results indicated that the culture medium B2 is the best subculture medium in this experiment.

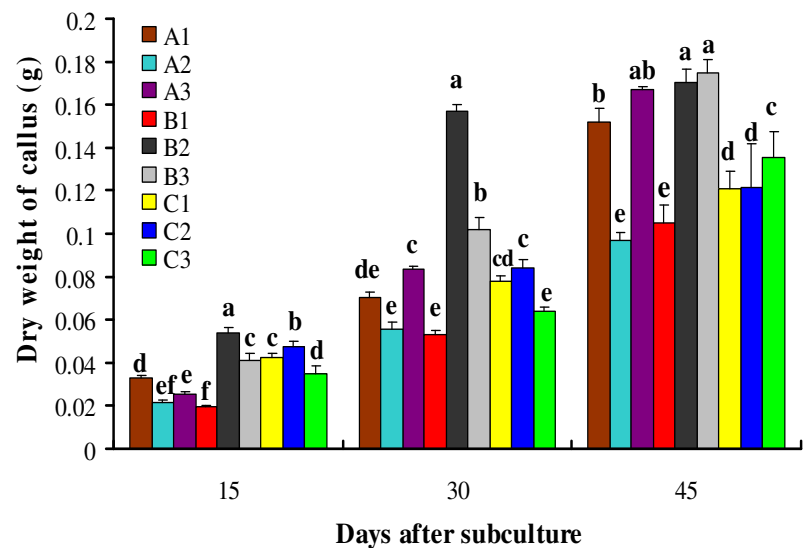

Fig. 3. The dry weight of Ginkgo callus after subculture on different culture media. Values are the mean of nine callus samples and bars represent standard errors. Means with the different letters are significantly difference at $P \leq 0.05$ by Duncan's multiple rang test
Effect of Different Concentrations of NAA and 6-BA on the Contents of Flavonoids and Terpene Lactones

The flavonoid content of the callus in the different culture media, except for culture medium C1, increased as the subculturing cycle was prolonged. After subculturing, the flavonoid content in the callus cultivated in medium B2 was significantly $(P \leq 0.05)$ higher than that in the callus cultivated in the other media and peaked on the 45th day (1.25\%, Fig. 4). Unlike the changes in flavonoid content, the terpene lactone content of the callus grown in each culture medium initially increased and then decreased after subculturing (Fig. 5). The terpene lactone content was the highest in culture medium B2, peaked on the 30th day at $0.078 \%$, which was significantly $(P \leq 0.05)$ higher than the terpene lactone contents in the other calluses. In terms of flavonoid and terpene lactone contents, the optimal subculture medium is $\mathrm{B} 2$ (MS + NAA: $2.0 \mathrm{mg} / \mathrm{L}+6-\mathrm{BA}$ $1.0 \mathrm{mg} / \mathrm{L}$ ) and the best subculturing cycle is $30 \mathrm{~d}$.

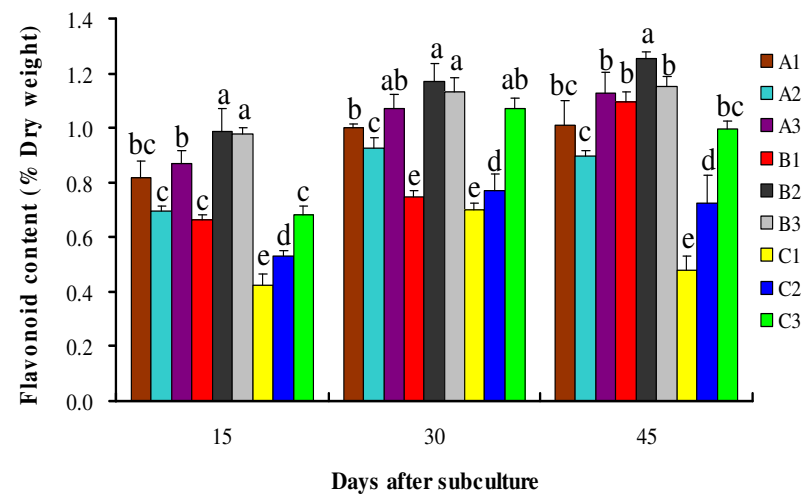

Fig. 4. The flavonoid content of Ginkgo callus after subculture on different culture media. Values are the mean of nine callus samples and bars represent standard errors. Means with the different letters are significantly difference at $P \leq 0.05$ by Duncan's multiple rang test

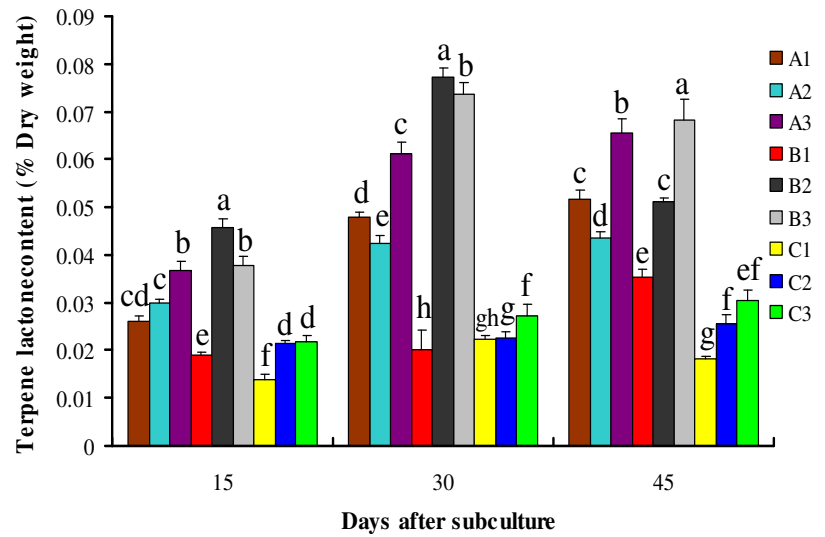

Fig. 5. The terpene lactone content of Ginkgo callus after subculture on different culture media. Values are the mean of nine callus samples and bars represent standard errors. Means with the different letters are significantly difference at $P \leq 0.05$ by Duncan's multiple rang test 


\section{Discussion}

In this study, the embryo-derived callus of Gingko was treated with different concentrations of NAA and 6-BA. Comparison of the induction of the Gingko callus in each culture medium showed that the growth indices (including growth, vitality, color and granulation) of the callus was better in the culture medium composed of MS+NAA 2.0 $\mathrm{mg} / \mathrm{L}+6-\mathrm{BA} 2.0 \mathrm{mg} / \mathrm{L}$ than in the other culture media. Thus, the culture medium composed of MS+NAA 2.0 $\mathrm{mg} / \mathrm{L}+6-\mathrm{BA} 2.0 \mathrm{mg} / \mathrm{L}$ may be considered optimal for inducing embryo-derived callus. The flavonoid and terpene lactone contents in the callus gradually increased as the subculture period was prolonged. This process is related to the growth of the callus being accelerated by the concentration of hormones (Fang et al., 2006; Sabater-Jara et al., 2013). The results also indicate that the best subculturing cycle is $30 \mathrm{~d}$.

Numerous studies have demonstrated that exogenous hormones can regulate the accumulation of endogenous hormones and then induce differentiation in explants. Chen et al. (1997) showed that different combinations of hormones can affect the biological yield of leaf-derived callus. The present study showed that the interaction between NAA and 6-BA can influence callus production. High concentrations of 6-BA can increase the biological yield of embryo-derived callus when the concentration of NAA is $2 \mathrm{mg} / \mathrm{L}$ after $30 \mathrm{~d}$ of subculturing. Previous studies indicated that different exogenous hormones can affect secondary metabolites (Camper et al., 1997). In the present study, we found that the MS culture medium added with 2 $\mathrm{mg} / \mathrm{L} \mathrm{NAA}$ and $1 \mathrm{mg} / \mathrm{L}$ 6-BA has a greater effect on the accumulation of flavonoids and terpene lactones in the callus from ginkgo embryo compared with the other culture media. Our results showed that the concentration of NAA has a greater influence on the accumulation of secondary metabolites than that of 6-BA. Excessively high or low concentrations of NAA decrease the production of flavonoids and terpene lactones. High concentrations of NAA reduce the production of secondary metabolites to a greater degree than low concentrations of NAA. This result could be attributed to the fact that high concentrations of auxin inhibit the production of flavonoids and terpene lactones (Sun et al., 2011). Kim et al. (1999) reported that the content of flavonoids in the callus decreased as the biological production of callus increased. However, the present results showed that the flavonoid content increased and the terpene lactone content decreased as the production of callus increased. This finding may be caused by the different phytohormone concentrations or culture conditions.

Accumulated evidence suggested that the calluses induced from different Ginkgo explants might possess different contents of flavonoids and terpene lactones. For instance, Chen et al. (1997) demonstrated that the leafderived callus possessed the highest content of flavonoids. Subsequently, the flavonoid content of stem-derived calluses is significantly higher than that of the cotyledon-derived calluses. The flavonoid content in embryo-derived callus in the present study $(1.254 \%$ highest in subculture medium on $45 \mathrm{~d}$ ) is lower than that in the leaf-derived callus of G. biloba studied by Chen et al. (1997) [1.510\% of dry weight (DW)], similar to that in the leaf-derived callus studied by Hao et al. (2009, 1.245\% DW) and higher than that in the leaf-derived callus studied by Jiang et al. (2000, 0.050\% $\mathrm{DW})$. In fact, the leaf-derived calluses in the abovementioned studies were obtained using different culture media and exogenous hormones. Therefore, the synergistic effect of explants and culture medium are effective in the production of secondary metabolites of Ginkgo callus. In terms of terpene lactones, most studies have investigated the effect of various elicitors on the production of bilobalide and ginkgolides in G. biloba cell cultures (Sabater-Jara et al., 2013). In spite of this, Boonkaew (2001) studied the effect of the source of explant and culture medium on the production of terpene lactones in G. biloba callus. The results showed that the total ginkgolide and bilobalide content in the root-derived callus was higher than that in the leaf-derived callus when grown on MSMO media. Although the highest terpene lactone content in the embryo-derived callus $(0.077 \% \mathrm{DW})$ in the present study was higher than that in the root-derived $(0.053 \% \mathrm{DW})$ and leaf-derived calluses $(0.038 \%$ DW) studied by Boonkaew (2001) and Balz et al. (1999), respectively, but it was generally lower than that in the cell cultures studied by Laurain et al. (1997), Park et al. (2004) and Kang et al. (2006a, 2006b, 2010). These results indicated that the method of tissue culture is a crucial factor in accumulation of terpene lactone in G. biloba cultures.

Tab. 2. Effect of different growth regulators on callus induction and growth from Ginkgo embryo. Values of growth increment are the mean of nine callus samples and bars represent standard errors

\begin{tabular}{ccccc}
\hline \multirow{2}{*}{$\begin{array}{c}\text { Medium } \\
\text { Code }\end{array}$} & $\begin{array}{c}\text { \%explants } \\
\text { producing } \\
\text { callus }\end{array}$ & \multicolumn{3}{c}{ Growth increment $(\mathrm{cm})$} \\
\cline { 3 - 5 } & 55.6 & $3.24 \pm 0.19 \mathrm{c}$ & $1.50 \pm 0.31 \mathrm{f}$ & 0 \\
\hline $\mathrm{A} 1$ & 58.3 & $2.56 \pm 0.57 \mathrm{~cd}$ & $4.35 \pm 0.28 \mathrm{c}$ & $0.18 \pm 0.02 \mathrm{e}$ \\
$\mathrm{A} 2$ & 63.9 & $2.60 \pm 0.21 \mathrm{~cd}$ & $5.38 \pm 0.35 \mathrm{~b}$ & 0 \\
$\mathrm{~A} 3$ & 79.2 & $3.96 \pm 0.72 \mathrm{~b}$ & $3.72 \pm 0.23 \mathrm{~d}$ & $0.51 \pm 0.03 \mathrm{~d}$ \\
$\mathrm{~B} 1$ & 84.7 & $4.15 \pm 0.55 \mathrm{ab}$ & $6.57 \pm 0.36 \mathrm{~b}$ & $1.27 \pm 0.07 \mathrm{~b}$ \\
$\mathrm{~B} 2$ & 94.4 & $2.93 \pm 0.30 \mathrm{c}$ & $11.84 \pm 0.41 \mathrm{a}$ & $2.50 \pm 0.14 \mathrm{a}$ \\
$\mathrm{B} 3$ & 83.3 & $4.42 \pm 0.19 \mathrm{a}$ & $3.86 \pm 0.60 \mathrm{~d}$ & $0.85 \pm 0.12 \mathrm{c}$ \\
$\mathrm{C} 1$ & 80.6 & $1.55 \pm 0.24 \mathrm{e}$ & $3.10 \pm 0.49 \mathrm{e}$ & 0 \\
$\mathrm{C} 2$ & 81.9 & $2.29 \pm 0.15 \mathrm{~d}$ & $3.06 \pm 0.33 \mathrm{e}$ & 0 \\
\hline $\mathrm{C} 3$ & & & & \\
\hline
\end{tabular}

The study of the molecular biology involved in the biosynthetic pathway of flavonoids and terpene lactones in Gingko has made breakthroughs in recent years. Many key enzyme genes of flavonoids and terpene lactones have been isolated and identified from Gingko. Our group and Tang's group have cloned and characterized several genes involved in the flavonoid biosynthetic pathway. These genes include phenylalanine ammonia-lyase (Xu et al., 2008a), chaconne synthase (Pang et al., 2005; Xu et al., 2007), flavanone 3hydroxylase (Shen et al., 2006), chalcone isomerase (Cheng et al., 2011), flavonol synthase (Xu et al., 2012), dihydroflavonol-4-reductase (Hua et al., 2013), and anthocyanidin synthase (Xu et al., 2008b). Besides, most of genes related to the biosynthetic pathway of terpene lactones have also been isolated and identified. These genes 
92

include levopimaradiene synthase (Schepmann et al., 2001), mevalonate diphosphate (Pang et al., 2006), 1-deoxy-Dxylulose 5-phosphate synthase (Kim et al., 2006a), 1-deoxyD-xylulose 5-phosphate reductoisomerase (Kim et al., 2006a), 1-hydroxy-2-methyl-2-(E)-butenyl-4-diphosphate synthase (Kim and Kim, 2010), 1-hydroxy-2-methyl-2-(E)butenyl 4-diphosphate reductase (Kim et al., 2008a), 2-Cmethyl-D-erythritiol 4-phosphate cytidyltransferase (Kim et al., 2006b), 2-C-methyl-D-erythritiol 2,4-cyclodiphosphate synthase (Kim et al., 2006c), and 4-(cytidine 5'-diphospho)2-C-methyl-D-erythritol kinase (Kim et al., 2008b). The time and spatial expression patterns of certain key genes indicated that the expression level of these key genes had significantly positive correlation with the flavonoid or terpene lactone contents of Gingko. However, these key genes have not been used in the genetic transformation of Gingko. A callus culturing system was established in this study, which provides important technical support for the genetic transformation of Gingko embryo for key genes involved in secondary metabolism, inducing transgenic callus, and then obtaining the callus cell line, the richest in flavonoids and terpene lactones.

\section{Conclusions}

This study showed that the optimal media for induced G. biloba embryo callus and subculture of callus were MS + NAA $2.0 \mathrm{mg} / \mathrm{L}+6-\mathrm{BA} 2.0 \mathrm{mg} / \mathrm{L}$, and culture medium MS + NAA $2.0 \mathrm{mg} / \mathrm{L}+6-\mathrm{BA} 1.0 \mathrm{mg} / \mathrm{L}$, respectively. The flavonoid and terpene lactone contents in the callus gradually increased as the subculture period was prolonged. However, the best subculturing cycle and the optimum culture medium for production of flavonoids and terpene lactones were $30 \mathrm{~d}$, and MS+NAA $(2.0 \mathrm{mg} / \mathrm{L})+6-\mathrm{BA}(1.0$ $\mathrm{mg} / \mathrm{L}$ ), respectively. The protocol in the present work may have valuable application for obtaining the callus cell line from G. biloba embryo that is the richest in flavonoids and terpene lactones.

\section{Acknowledgments}

This work was supported by National Natural Science Foundation of China (31370680, 31000904, and 31270717), Key Project of Chinese Ministry of Education (212112), the Natural Science Foundation of Hubei Province (2013CFA039), Open Fund of Hubei Key Laboratory of Economic Forest Germplasm Improvement and Resources Comprehensive Utilization (No. 20011BLKF240, No. 2013000803), and UniversityIndustry Cooperation Fund of Hubei Educational Office (CXY2009B009).

\section{References}

Balz JP, Courtois D, Drieu J, Drieu K, Reynoird JP, Sohier C, Teng BP, Touché A, Petiard V (1999). Production of ginkgolides and bilobalide by Ginkgo biloba plants and tissue cultures. Planta Med 65:620-626.

Bilia AR (2002). Ginkgo biloba L. Fitoterapia 73:276-279.
Boonkaew T (2001). In vitro culture of Gingko biloba L. Clemson University, South Carolina, Ph. D Dissertation.

Camper ND, Coker PS, Wedge DE, Keese RJ (1997). In Vitro culture of Ginkgo. In Vitro Cell Dev Biol Plant 33:125-127.

Carrier D, Chauret N, Mancini M, Coulombe P, Neufeld R, Weber M, Archambault J (1991). Detection of ginkgolide A in Ginkgo biloba cell cultures. Plant Cell Rep 10:256-259.

Chen XS, Deng XX, Zhang WC (1997). Effects of medium and culture environment on flavonoid production of Ginkgo biloba callus. Acta Hortic Sinica 24(4):373-377.

Cheng H, Li L, Cheng S, Cao F, Wang F, Yuan H (2011). Molecular cloning and function assay of a chalcone isomerase gene (GbCHI) from Ginkgo biloba. Plant Cell Rep 30:49-62.

Fang J, Que G, Han Y (2006). Several factors affecting accumulation of flavonoids in suspension-cultured cells of Ginkgo biloba. Forest Res 19(1):51-53.

Hao G, Du X, Zhao F, Shi R, Wang J (2009). Role of nitric oxide in UV-B-induced activation of PAL and stimulation of flavonoid biosynthesis in Ginkgo biloba callus. Plant Cell Tiss Organ Cult 97:175-185.

Hao G, Du X, Zhao F, Ji H (2010). Fungal endophytes-induced abscisic acid is required for flavonoid accumulation in suspension cells of Ginkgo biloba. Biotechnol Lett 32:305-314.

Hua C, Linling L, Shuiyuan C, Fuliang C, Feng X, Honhhui Y, Conghua W (2013). Molecular cloning and characterization of three genes encoding dihydroflavonol-4-reductase from Ginkgo biloba in anthocyanin biosynthetic pathway. PloS One 8(8):e72017.

Jiang L, Zhang W, Ke Y (2000). Effect of five macronutrients on cell growth and synthesis of flavonol of glycosides of Ginkgo callus in vitro. Acta Hortic Sinica 27(2):130-132.

Kang S, Min J, Kim Y, Park D, Jung H, Karigar C, Ha Y, Kim SW, Choi MS (2006a). Effect of supplementing terpenoid biosynthetic precursors on the accumulation of biolobalide and ginkgolides in Ginkgo biloba cell cultures. J Biotechnol 123:85-92.

Kang SM, Min JY, Kim YD, Kang YM, Park DJ, Jung HN, Kim SW, Choi MS (2006b). Effects of methyl jasmonate and salicylic acid on the production of bilobalide and ginkgolides in cell cultures of Ginkgo biloba. In Vitro Cell Dev Biol Plant 42:44-49.

Kang S, Min J, Kim Y, Karigar C, Kim S, Goo G, Choi M (2009). Effect of biotic elicitors on the accumulation of bilobalide and ginkgolides in Ginkgo biloba cell cultures. J Biotechnol 139:8488.

Kang SM, Min JY, Park DJ, Jeong MJ, Song HJ, Heo CM, Kim HG, Yang JK, Lee CH, Karigar CS (2010). Potassium chloride elicits enhancement of bilobalide and ginkgolides production by Ginkgo biloba cell cultures. Forest Sci Technol 6:49-54.

Kim M, Lee W, Kim H, Kim C, Ryu Y (1998). Effect of environmental factors on flavonol glycoside production and 
phenylalanine ammonia-lyase activity in cell suspension cultures of Ginkgo biloba. J Microbiol Biotechnol 8(3):237244.

Kim M, Kim C, Jo DH, Ryu YW (1999). Effect of fungal elicitor and heavy metals on the production of flavonol glycosides in cell cultures of Ginkgo biloba. J Microbiol Biotechnol 9:661667.

Kim SM, Kuzuyama T, Chang YJ, Song KS, Kim SU (2006a). Identification of class 2 1-deoxy-D-xylulose 5-phosphate synthase and 1-deoxy-D-xylulose 5-phosphate reductoisomerase genes from Ginkgo biloba and their transcription in embryo culture with respect to ginkgolide biosynthesis. Planta Med 72:234-240.

Kim SM, Kuzuyama T, Chang YJ, Kwon HJ, Kim SU (2006b). Cloning and functional characterization of $2-\mathrm{C}$-methyl- ${ }_{-}{ }^{-}$ erythritiol 4-phosphate cytidyltransferase (GbMECT) gene from Ginkgo biloba. Phytochemistry 67:1435-1441.

Kim SM, Kuzuyama T, Chang YJ, Kim SU (2006c). Cloning and characterization of 2-C-methyl- ${ }_{D}$-erythritiol 2,4 cyclodiphosphate synthase (MECS) gene from Ginkgo biloba. Plant Cell Rep 25:829935.

Kim SM, Kuzuyama T, Kobayahsi A, Sando T, Chang YJ, Kim SU (2008a). 1-Hydroxy-2-methyl-2-(E)-butenyl 4diphosphate reductase (IDS) is encoded by multicopy genes in gymnosperms Ginkgo biloba and Pinus taeda. Planta 227:287298.

Kim SM, Kim YB, Kuzuyama T, Kim SU (2008b). Two copies of 4-(cytidine 5'-diphospho)-2-C-methyl- ${ }^{-}$ erythritol kinase (CMK) gene in Ginkgo biloba: molecular cloning and functional characterization. Planta 228:941-950.

Kim SM, Kim SU (2010). Characterization of 1-hydroxy-2methyl-2-(E)-butenyl-4-diphosphate synthase (HDS) gene from Ginkgo biloba. Mol Biol Rep 37:973-979.

Laurain D, Trémouillaux-Guiller J, Chénieux JC, van Beek TA (1997). Production of ginkgolide and bilobalide in transformed and gametophyte derived cell cultures of Ginkgo biloba. Phytochemistry 46:127-130.

Liao Y, Xu F, Zhu J, Wang Y, Cheng S (2008). Separation and determination of terpene trilactiones by gas chromatography with wide bore capillary column. Acta Agric Borealioccidentalis Sinica 17:146-149.

Lu S, Guo X, Zhao P (2011). Effect of Ginkgo biloba extract 50 on immunity and antioxidant enzyme activities in ischemia reperfusion rats. Molecules 16:9194-9206.

Mahadevan S, Park Y (2008). Multifaceted therapeutic benefits of Ginkgo biloba L.: chemistry, efficacy, safety, and uses. J Food Sci 73(1):R14-19.

Murashige T, Skoog F (1962). A revised medium for rapid growth and bioassays with tobacco tissue cultures. Physiol Plant 15:473-497.
Nakanishi K (2005). Terpene tractions from Ginkgo biloba: from ancient times to the 21st century. Bioorg Med Chem 13:4987-5000.

Pang Y, Shen G, Wu W, Liu X, Lin J, Tan F, Sun X, Tang K (2005). Characterization and expression of chalcone synthase gene from Ginkgo biloba. Plant Sci 168:1525-1531.

Pang Y, Shen G, Bergès T, Cardier H, Wu W, Sun X, Tang K (2006). Molecular cloning, characterization and heterologous expression in Saccharomyces cerevisiae of a mevalonate diphosphate decarboxylase cDNA from Ginkgo biloba. Physiol Plant 127:19-27.

Park Y, Kim S, Jung H, Kang Y, Kang S, Prasad D, Kim S, Choi M (2004). Variation of ginkgolides and bilobalide content in leaves and cell cultures of Ginkgo biloba L. Biotechnol Bioprocess Eng 9:35-40.

Sabater-Jara A, Souliman-Youssef S, Novo-Uzal E, Almagro L, Belchí-Navarro S, Pedreño M (2013). Biotechnological approaches to enhance the biosynthesis of ginkgolides and bilobalide in Ginkgo biloba. Phytochem Rev 12:191-205.

Schepmann, HG, Pang J, Matsuda SPT (2001). Cloning and characterization of Ginkgo biloba levopimaradiene synthase, which catalyzes the first committed step in ginkgolide biosynthesis. Arch Biochem Biophys 392:263-269.

Shen G, Pang Y, Wu W, Deng Z, Zhao L, Cao Y, Sun X, Tang K (2006). Cloning and characterization of a flavanone 3hydroxylase gene from Ginkgo biloba. Biosci Rep 26:19-29.

Sun N, Xu F, Huang X, Cheng S, Wang Y (2011). Advances in tissue culture and molecular biology of secondary metabolism in Ginkgo biloba. Guizhou Agri Sci 39(10):27-31.

Van Beek TA (2002). Chemical analysis of Ginkgo biloba leaves and extracts. J Chromatogr A 967:21-55.

Van Beek T, Montoro P (2009). Chemical analysis and quality control of Ginkgo biloba leaves, extracts, and phytopharmaceuticals. J Chromatogr A 1216:2002-2032.

Xu F, Cheng SY, Cheng SH, Wang Y, Du HW (2007). Time course of expression of chalcone synthase gene in Ginkgo biloba. J Plant Physiol Mol Biol 33:309-31.

Xu F, Cai R, Cheng S, Du H, Wang Y, Cheng S (2008a). Molecular cloning, characterization and expression of phenylalanine ammonia-lyase gene from Ginkgo biloba. Afr J Biotechnol 7:721-729.

Xu F, Cheng H, Cai R, Li LL, Chang J, Zhu J, Zhang FX, Chen LJ, Wang Y, Cheng SH, Cheng SY (2008b). Molecular cloning and function analysis of an anthocyanidin synthase gene from Ginkgo biloba, and its expression in abiotic stress responses. Mol Cells 26:536-547.

Xu F, Li L, Zhang W, Cheng H, Sun N, Cheng S, Wang Y (2012). Isolation, characterization, and function analysis of a flavonol synthase gene from Ginkgo biloba. Mol Biol Rep 39:2285-2296. 